\title{
Afzelin inhibits migration of MDA-MB-231 cells by suppressing FAK expression and Racl activation
}

\author{
Eva Rachmi ${ }^{1,2 *}$, Basuki Bambang Purnomo ${ }^{3}$, Agustina Tri Endharti ${ }^{4,5}$, Loeki Enggar Fitri ${ }^{4,5}$ \\ ${ }^{1}$ Doctoral Program in Medical Science, Faculty of Medicine, Universitas Brawijaya, Malang, Indonesia. \\ ${ }^{2}$ Department of Anatomy, Faculty of Medicine, Universitas Mulawarman, Samarinda, Indonesia. \\ ${ }^{3}$ Department of Urology, Faculty of Medicine, Universitas Brawijaya/dr Saiful Anwar General Hospital, Malang, Indonesia. \\ ${ }^{4}$ Department of Parasitology, Faculty of Medicine, Universitas Brawijaya, Malang, Indonesia. \\ ${ }^{5}$ Biomedical Central Laboratory, Faculty of Medicine, Universitas Brawijaya, Malang, Indonesia.
}

\section{ARTICLE INFO \\ Received on: 07/10/2019 \\ Accepted on: 24/11/2019 \\ Available online: 03/01/2020}

Key words:

Afzelin, TNBC,

cell migration, FAK, Rac1.

\begin{abstract}
Triple-negative breast cancer (TNBC) has the worst prognosis and the highest rate of metastasis among other types of breast cancer. These characteristics are supported by the dysregulation of focal adhesion kinase (FAK) and Rac1 which are the key players of mesenchymal cell migration on TNBC. Afzelin is a secondary metabolite that is contained in a variety of plants. This study explored the anti-migration effect of afzelin and its interaction with FAK and Rac1 on the highly invasive TNBC cell line, MDA-MB-231. Cell viability was assessed by 3-(4,5-dimethyl 2-thiazolyl)-2,5diphenyltetrazolium bromide assay, and cell migration was evaluated using in vitro scratch assay. Rac1 activation was analyzed using the colorimetric assay, while vinculin and actin filaments were stained through immunofluorescence. The quantity of total FAK and phosphorylated FAK tyr397 was detected by Western blotting. Afzelin decreased cell viability and inhibited two-dimensional cell migration in a dose-dependent manner. Under confocal laser scanning microscopy, vinculin localization at the cell edge demonstrated a reduction of focal adhesion formation by afzelin. Further exploration showed that afzelin decreased FAK expression but did not affect FAK phosphorylation at tyr397. In addition, afzelin decreased Rac1-GTPase activation, which is a downstream effector of FAK. Taken together, these results suggest that afzelin suppresses TNBC cell migration, through inhibition of FAK expression and Rac1-GTPase activation.
\end{abstract}

\section{INTRODUCTION}

Breast cancer ranks as the second-highest incidence in women and is the leading cause of cancer deaths in 135 countries (Bray et al., 2018). The five-year survival rate of breast cancer patients decreases dramatically when distant metastases occur (Howlader et al., 2016). Among breast cancer subtypes, triple-negative breast cancer (TNBC) has the worst prognosis, particularly in the first three years after the diagnosis (Dai et al., 2015; Ovcaricek et al., 2011). TNBC tends to metastasize the visceral organs and the central nervous system (Anders and Carey,

\section{${ }^{*}$ Corresponding Author}

Eva Rachmi, Doctoral Program in Medical Science, Universitas Brawijaya, Malang, Indonesia; Department of Anatomy, Medical Faculty, Universitas Mulawarman, Samarinda, Indonesia.

E-mail: e.rahmi@fk.unmul.ac.id
2009), which lead to only 13 months of median overall survival (Bacalbasa and Ionescu, 2016).

The inhibition of metastasis is challenging because it involves a cascade of processes, each of which has its own requirements. However, the ability of metastatic cells to migrate is a common characteristic in almost all steps, which can be targeted in inhibiting metastasis (Mackay, 2008; Wells et al., 2013). Cell migration occurs through a cycle consisting of membrane protrusion, focal adhesion formation, extracellular matrix protease secretion, contraction of stress fibers, and rear cell retraction (Friedl and Wolf, 2003).

Focal adhesion kinase (FAK) as an adapter of focal adhesion and Racl as a modulator of cytoskeletal rearrangement in the lamellipodia formation play a crucial role in the migration mechanism. Both were found to be hyperactivated in various types of solid cancers (Lou et al., 2018; Yoon et al., 2015), which could be caused by abnormal upstream inputs, overexpression, or 
deregulated degradation (De et al., 2019). In TNBC, dysregulation of FAK (Golubovskaya et al., 2014) and Rac1 (Tsai et al., 2015) is associated with increased invasion, metastasis, and poor prognosis. Inhibition of TNBC invasion could be achieved by suppressing FAK (Taliaferro-Smith et al., 2015) or Rac1 (Morimura and Takahashi, 2011) activation.

Previous studies supported afzelin potential as anticancer. In breast cancer cells, estrogen receptor-positive subtype, afzelin increases apoptosis through caspase cascade activation (Diantini et al., 2012). The ability of afzelin to activate caspase cascade is also shown in androgen-sensitive prostate cancer (Halimah et al., 2015). In addition, afzelin inhibits proliferation and cell cycle of prostate cancer cells that are both androgen-sensitive or independent (Zhu et al., 2015). Afzelin shares characteristics with other flavonols in terms of structural similarity with adenine. Therefore, afzelin is predicted to compete with ATP in the ATP-binding enzyme. The addition of rhamnoside groups makes afzelin structure unique, hence it might inhibit kinases more selectively (Smith et al., 2005; Utepbergenov et al., 2012). For this reason, it is necessary to prove the ability of afzelin to inhibit migration in TNBC, through the suppression of FAK expression and Racl activation. The effects will be proven in M.D. Anderson-Metastatic Breast-231 (MDA-MB 231) cells, as the TNBC model whose characteristics are most explored and most frequently used in research (VolkDraper and Rajput, 2012).

\section{MATERIALS AND METHODS}

\section{Treatment material}

Afzelin was purchased from ChemFaces ${ }^{\circledR}$ (CFN98757). Afzelin was prepared in dimethyl sulfoxide (DMSO) prior to each treatment and diluted with appropriate cell culture medium to desired concentration $(100,200,400$, and $800 \mu \mathrm{g} / \mathrm{ml})$.

\section{Cell culture}

Human MDA-MB-231 breast cancer cells (ATCC $^{\circledR}$ HTB-26 ${ }^{\mathrm{TM}}$ ) were maintained in Dulbecco's modified Eagle's medium-high glucose supplemented with $10 \%$ fetal bovine serum (FBS), 1\% non-essential amino acids, and 1\% penicillinstreptomycin $\left(\mathrm{GIBCO}^{\mathrm{TM}}\right)$. The cells were incubated at $37^{\circ} \mathrm{C}$ in an incubator with $5 \% \mathrm{CO}_{2}$ at $90 \%$ confluence.

\section{Cell viability assay}

Cell viability was assayed by the 3-(4,5-dimethyl 2-thiazolyl)-2,5-diphenyltetrazolium bromide (MTT) reduction method. Briefly, MDA-MB-231 cells were seeded in 96-well plates at a density of $1 \times 10^{4}$ cells/well and cultured for 48 hours, followed by treatment with various afzelin concentrations $(0,100$, 200,400 , and $800 \mu \mathrm{g} / \mathrm{ml}$ ) for overnight. Next, $15 \mu \mathrm{l}$ MTT solution $(0.5 \mathrm{mg} / \mathrm{ml})$ was added to the culture for another 4 hours, and the medium was subsequently removed. The formed formazan crystals were dissolved by adding $100 \mu \mathrm{l}$ of DMSO. The absorbance of each well was measured at $570 \mathrm{~nm}$ by a microplate reader (BioRad Laboratories, USA).

\section{Migration assay}

Cell migration was evaluated using in vitro scratch assay. For this random cell migration, MDA-MB 231 cells were plated in $24-w e l l$ plates at $80 \%-90 \%$ confluence. The culture monolayers were wounded with a p200 pipette tip, washed twice with complete medium to remove cell debris, and then treated with serum-starved media $(0.5 \%$ FBS $)$ containing afzelin. The wells were re-evaluated within 24 and 48 hours. The wounded area was re-photographed in two areas, under an inverted microscope at $400 \times$. Cell migration was determined by examining the area occupied by the cells (Lewis et al., 2019) and the number of cells in the wounded area (Tantivejkul et al., 2003) assisted by ImageJ software. The area measurement was done through a Montpellier Ressources Imagerie Wound Healing plugin. The cell-occupied area was a cell-free area at 0 -hour subtracted by a cell-free area at the time of observation ( 24 or 48 hours) as a percentage of cellfree area at 0 -hour.

\section{Rac1 activation assay}

Afzelin inhibition of Rac1 activation in MDA-MB-231 cells was analyzed using the colorimetric-based Rac1 G-LISA ${ }^{\text {TM }}$ Activation Assay Kit (CytoskeletonInc; Denver, CO). MDAMB-231 cells were plated in a 24-well plate with complete media. After reaching $60 \%-70 \%$ confluence, the media was replaced with starvation media (FBS $0.5 \%$ ) containing different concentrations of afzelin for 24 hours. Cells were washed with ice-cold phosphate-buffered saline (PBS) and then added with serum-free media containing epidermal growth factor (EGF) 50 $\mathrm{ng} / \mathrm{ml}$ for 5 minutes (Zhang et al., 2015). Subsequently, the cells were lysed and active-Rac-1 levels of the lysate were quantified according to the manufacturer procedure. Equal amounts of protein per sample lysate were determined by the UV-VIS spectrophotometer (NanoDrop ${ }^{\mathrm{TM}}$, Thermofisher). Active Rac1 levels were expressed as a fold increase over the active Rac1 levels in control conditions.

\section{Focal adhesion formation}

MDA-MB-231 were seeded on fibronectin-coated glass coverslips in a 24 -well plate with complete media for 24 hours. The cells treated with various concentrations of afzelin for 14 hours. After removing the media, the cells were fixed with paraformaldehyde $4 \%$ and then washed two times with PBS. Vinculin and actin filaments were stained with actin cytoskeleton and focal adhesion staining kit FAK100 (Merck-Millipore, USA), according to the manufacturer's instructions. Focal adhesion and actin were visualized by a confocal laser scanning microscope FV 1000 (Olympus, USA) with $400 \times$ magnification.

\section{Western blot analysis}

MDA-MB-231 were cultured at 90\%-95\% confluence, washed with ice-cold PBS, and scrapped in radioimmunoprecipitation assay buffer (G-Biosciences, USA) containing phosphatase inhibitor (Medchemexpress, USA) and protease inhibitor (Sigma-Aldrich, USA). The total protein concentration of each treatment was measured utilizing a UV-VIS spectrophotometer (NanoDrop ${ }^{\mathrm{TM}}$, Thermofisher). Equal amounts of protein were then subjected to electrophoretic separation in sodium dodecyl sulfate polyacrylamide gels. The proteins were transferred to a nitrocellulose membrane, using a semi-dry transblot apparatus at 20 volts and $300 \mathrm{~mA}$ for 2 hours. Membranes were blocked overnight with $5 \%$ bovine serum albumin (BSA) at $4^{\circ} \mathrm{C}$, 
followed by probing with primary antibodies such as anti-FAK1 monoclonal (1:500) (bs-3159R) and anti-FAK tyr397 polyclonal (1:500) (bsm 50324M, Bioss Inc, USA) for 2 hours. Afterward, a secondary antibody was added for 2 hours and subsequently Strepavidin-Horse Radish Peroxidase for 1 hour. Bound proteins were detected using 3,3',5,5'-tetramethylbenzidine substrate in the darkroom. Gel quantifications were performed using ImageJ (Alečković et al., 2017).

\section{Statistical analysis}

For statistical analyses, results were reported as average \pm standard error mean. Analysis of variance followed post hoc analysis was used to explore possible pair-wise comparisons of means between different treatments. A $p$-value of $<0.05$ was considered statistically significant.

\section{RESULTS AND DISCUSSION}

\section{Afzelin reduced MDA-MB-231 cells viability}

Effect of afzelin on cell viability was estimated based on the premise that viable cells with active metabolism convert MTT into a purple-colored formazan product (Riss et al., 2016). The MTT assay showed a decrease of formazan formation along with the increase of afzelin dose. This result meant that afzelin reduced cell viability in a dose-dependent manner (Fig. 1). Through regression linear analysis, the the IC50 of afzelin on MDA-MB-231 cells was predicted to be $992 \mu \mathrm{g} / \mathrm{ml}$. Afzelin cytotoxicity on other cancer cell lines was also proven in previous publications such as estrogen-sensitive breast cancer cells (MCF-7), hepatocarcinoma cells (HC-04) (Diantini et al., 2012), and both androgen-dependent (LNCaP) and independent (PC-3) prostate cancer cells (Zhu et al., 2015).

\section{Afzelin inhibited MDA-MB-231 cells migration}

In the scratch monolayer assay model, afzelin inhibited two-dimensional cell migration in a dose-dependent manner. This result was demonstrated by the decrease in the number of

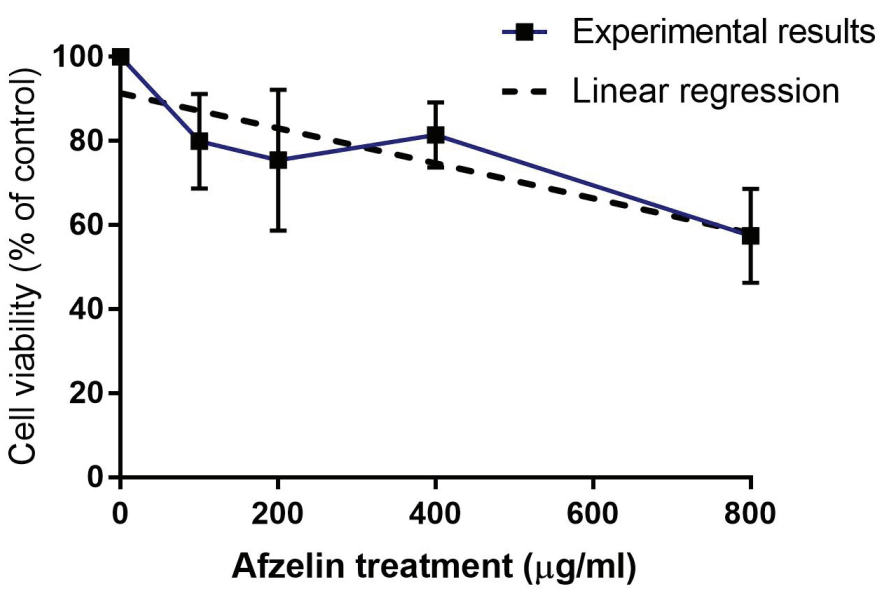

Figure 1. Cell viability assay in MDA-MB-231 cancer cell after overnight treatment of afzelin. The relative amount of viable cells was estimated by measuring cell suspension absorbance after MTT assay. Calculation of IC50 value was predicted through the trend line equation $(\mathrm{Y}=-0.0417 . \mathrm{X}+91.38)$ based on graph of cell viability versus afzelin concentration. Data were shown as mean + standard error mean (SEM). cells that migrated into the wounded area. Afzelin treatment at concentrations of 400 and $800 \mu \mathrm{g} / \mathrm{ml}$ suppressed the number of migrated cells, which was demonstrated by non-significant differences between observations at 24 and 48 hours (Fig. 2B).

The quantitative degree of migration was verified further by measuring the cell-covered area, which showed a similar trend with the decline of migrated cells (Fig. 2C). Compared to the number of cells, the analysis of the cellcovered area gave different results at $400 \mu \mathrm{g} / \mathrm{ml}$ afzelintreatment group, while observation after 48 hours showed a significant increase in migration compared to that of 24 hours. Afzelin treatment at $400 \mu \mathrm{g} / \mathrm{ml}$ was not inducing a drastic change in MDA-MB-231 cell morphology compared to $800 \mu \mathrm{g} / \mathrm{ml}$ where the cells became thinner and elongated (Fig. 3A). This event might explain why the increase of migrated cells could increase the occupied area significantly in $400 \mu \mathrm{g} / \mathrm{ml}$ afzelin-treatment group, even though the difference of migrated cell numbers between 24 and 48 hours was not significant. Afzelin inhibition of MDA-MB-231 cell migration in scratch assay might predict anti-metastatic potential in vivo (Adams et al., 2010; Choi et al., 2014; Li et al., 2017).

To explore the mechanism of the afzelin-mediated inhibition of cell migration, the focal adhesion formation was analyzed based on the vinculin localization in the edge of the cells. As compared to the control negative group, the focal adhesion formation was reduced following the increase of afzelin concentration (Fig. 3A). This result was in line with the decrease of two-dimensional migration that was induced by afzelin treatment. Although, in this study, we did not determine afzelin effect on the descriptor of focal adhesion (size, number, surface density, and shape), the decrease of migrated cell number and cell-covered area might be related with the diminishing of the focal adhesion size (reducing cell speed) or change of focal adhesion shape (reducing cell speed, final distance traveled, and persistence distance) (Kim and Wirtz, 2013).

\section{Afzelin inhibited FAK expression and Rac1 activation}

Afzelin effectively inhibited EGF-stimulated activation of Rac1 GTPase at 400 and $800 \mu \mathrm{g} / \mathrm{ml}$, which was diminished by $60 \%$ compared to the negative control (Fig. 3C). The formation of membrane protrusion as the initial step of migration is controlled by the Rho-GTPase family, with Rac-1 playing a crucial role. Rac1 regulates lamellipodia formation in response to growth factor receptors stimulation or integrin activation (Nobes and Hall, 1999). Lamellipodia provides forward cell traction. To achieve this function, focal adhesion (FA) needs to be formed in lamellipodia, which will connect integrins with extracellular matrix (outward) and with actin cytoskeleton (inward). Actin when connected with focal adhesion will contract and then produce stress fibers that pull the cell forward (Mack et al., 2011).

Focal adhesion kinase (FAK) is a nonreceptor tyrosine kinase and the main adaptor protein of FA that modulates adhesive interaction (Horton et al., 2016). FAK regulates cell motility, survival, and proliferation through the integration of growth factors and integrin-mediated signaling (Horton et al., 2016; Sieg et al., 2000). FAK activation by Src stimulates Rac1 activity through breast cancer anti-estrogen resistance (BCAR) 1 / downstream of Crk 


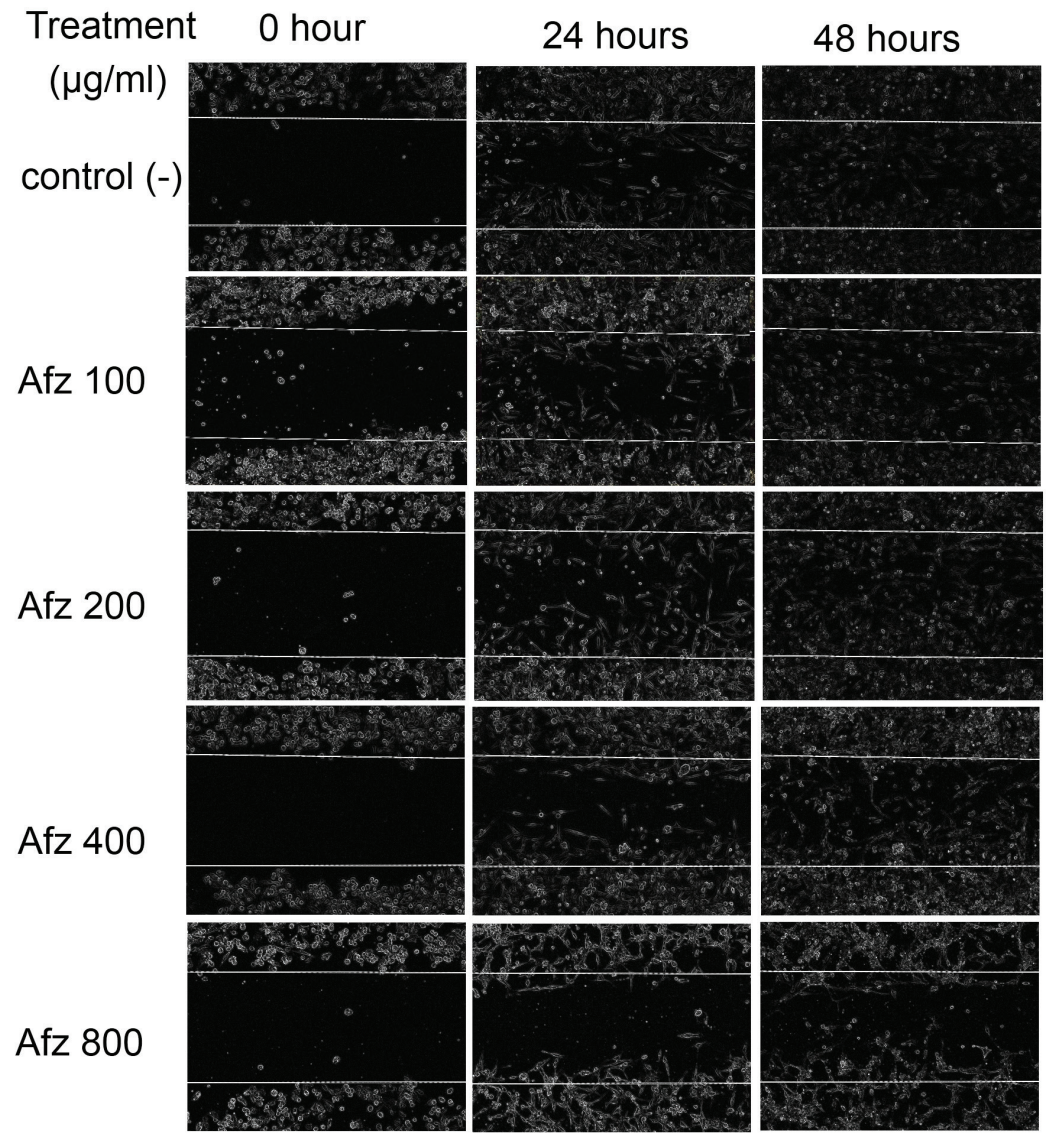

(A)

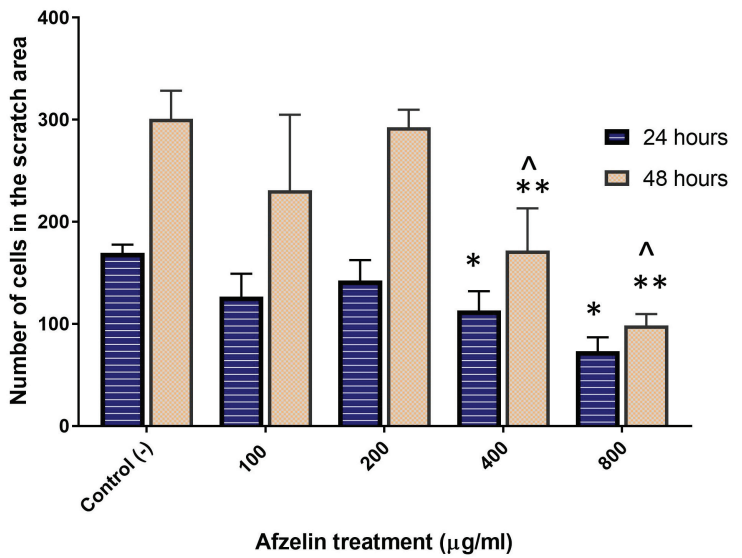

(B)

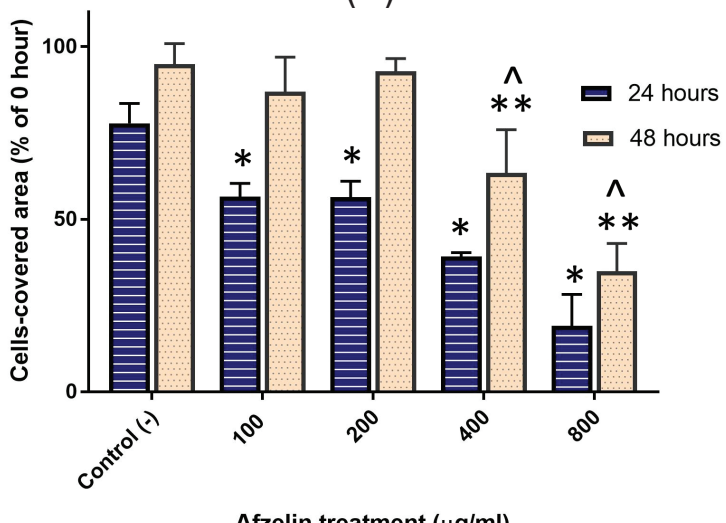

Afzelin treatment $(\mu \mathrm{g} / \mathrm{ml})$

(C)

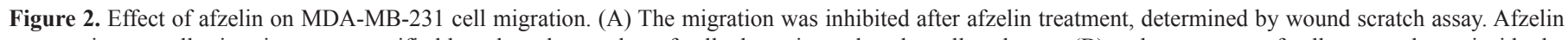



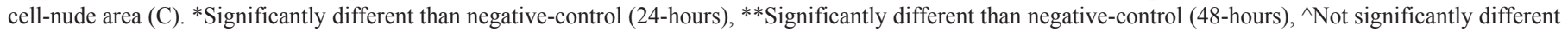
than 24-hours treatment. Data were shown as mean + SEM.

(DOCK)180/engulfment and cell motility (ELMO)1 signaling, with the DOCK180-ELMO1 complex serving as a guanine nucleotide exchange factor (GEF) for Rac1. The FAK-Src complex also activates the Pak-interacting exchange factor-beta, which is the GEF for Cdc42 and Rac1. Recruitment and activation of Rac1, in turn, will promote the formation of membrane cell protrusions (Danen, 2013; Huveneers and Danen, 2009). To evaluate the afzelin effect on FAK, the quantity of total FAK and phosphorylated FAK tyr397 was detected by Western blotting. During afzelin treatment, FAK expression was down-regulated, particularly at a dose of $800 \mu \mathrm{g} / \mathrm{ml}$. Meanwhile, afzelin suppression on FAK tyr397 phosphorylation might be due to its inhibition of FAK expression (Fig. 3B). If afzelin inhibits FAK tyr397 phosphorylation directly, the increase of afzelin concentration should have more effect on the reduction of phosphorylated FAK tyr397 than on the reduction of the total FAK.

Our results demonstrated that afzelin had the potential as the inhibitor of TNBC migration, through suppression of FAK expression and Rac1 activation. However, still there are questions that are needed to be further elucidated. In this study, afzelin affected the focal adhesion formation and Rac-1 activation at 400 $\mu \mathrm{g} / \mathrm{ml}$; on the other hand, afzelin affected FAK expression and FAK tyr397 phosphorylation at $800 \mu \mathrm{g} / \mathrm{ml}$.
These phenomena could be explained through some possibilities. First, considering that FAK activation is a sequential event involving several domains and amino acid phosphorylation following tyr397 activation, afzelin at a dose of $400 \mu \mathrm{g} / \mathrm{ml}$ probably inhibited FAK directly at other sites, such as phosphorylation of tyr576/577 at kinase domain or tyr925 at binding-site of Grb2. Second, afzelin possibly inhibited signal transduction downstream of FAK. Cell adhesion is formed through a dynamic process in the form of focal complexes, FA, or fibrillar adhesion. Focal complexes are small (less than 1 $\mu \mathrm{m}^{2}$ ) at the edges of spreading cells or leading edge of migrating cells, the components of which include vinculin and FAK. To be able to effectively migrate, focal complexes develop into FAs that involve other protein tyrosinases (Rikitake and Takai, 2011). At a concentration of $400 \mathrm{ug} / \mathrm{ml}$, afzelin might be able to downregulate signaling which contributed to focal complexes maturation into FA. Afzelin could possibly downregulate signaling protein downstream of the FAK-Src complex, including p130Cas, paxillin, BCAR, DOCK180, and ELMO1, or even directly inhibited Rac-1 activation. These hypotheses need further investigations. 


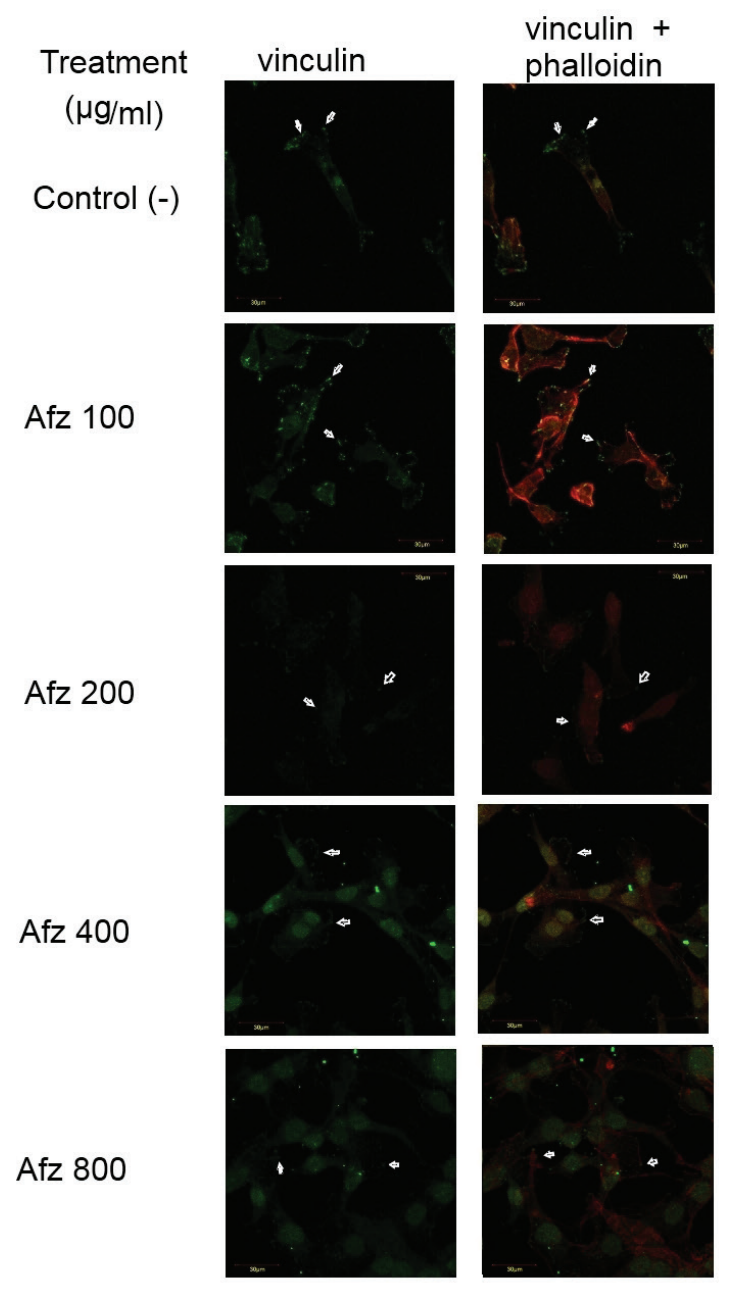

(A)

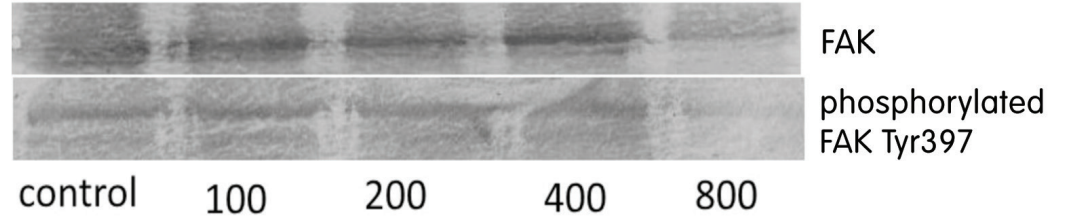

$(-)$

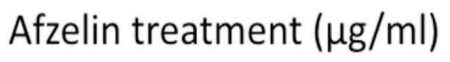

(B)

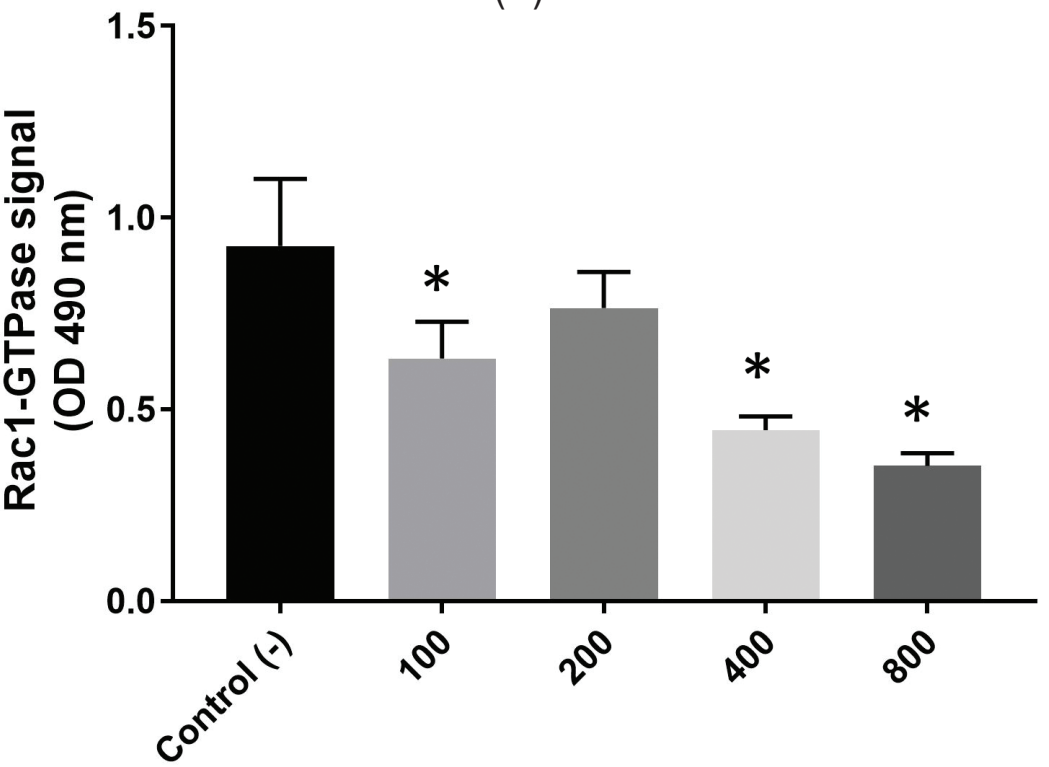

Afzelin treatment $(\mu \mathrm{g} / \mathrm{ml})$

(C)

Figure 3. Afzelin inhibited FA formation, FAK expression, and Rac1 activation in MDA-MB-231 cells. (A) After treated with various doses of afzelin, MDA-MB-231 cells were stained with anti-vinculin antibody (green) and TRITC-conjugated phalloidin (red). Focal adhesion was indicated by the arrow. Bar equals approximately $30 \mu \mathrm{m}$. (B) The effect of afzelin on FAK expression and FAK tyr397 phosphorylation was assessed qualitatively by Western blotting. (C) Quantification of Rac1 activation demonstrated downregulation by afzelin. * Significantly different than negative-control. Data were presented as mean + SEM.

\section{CONCLUSION}

In conclusion, afzelin exposures suppressed cell migration by reducing focal adhesion formation. Afzelin reduced FAK expression and subsequently FAK phosphorylation at tyr397. Besides, afzelin downregulates the activation of Rac1 GTPase. The inhibition of two-dimensional migration in vitro on MDA-MB-231 supports the prediction of anti-metastatic ability in vivo. These results firmly suggest that afzelin presents a potential anti-metastatic property and a good candidate for further testing as a potential compound or a bioisosteric template for drug development for TNBC metastasis inhibition.

\section{ACKNOWLEDGMENTS}

The authors would like to thank the Biomedical Central Laboratory team for providing support and feedback throughout this research.

\section{CONFLICTS OF INTEREST}

The authors declared that they have no conflict of

\section{FINANCIAL SUPPORT AND SPONSORSHIP}

\author{
None.
}

\section{AUTHORS' CONTRIBUTIONS}

Study concept and design: Eva Rachmi (ER), Basuki Bambang Purnomo (BBP), Agustina Tri Endharti (ATE), and Loeki Enggar Fitri (LEF). Acquisition, analysis, and interpretation of data: ER and LEF Drafting of the manuscript: ER Critical revision of the manuscript for intellectual content: ER, BBP, ATE, and LEF Agreement to be accountable for all aspects of the work: ER, BBP, ATE, LEF.

\section{REFERENCES}

Adams LS, Phung S, Yee N, Seeram NP, Li L, Chen S. Blueberry phytochemicals inhibit growth and metastatic potential of MDA-MB-231 breast cancer cells through modulation of the phosphatidylinositol 3-kinase pathway. Cancer Res, 2010; 70(9):3594-605.

Alečković M, Wei Y, LeRoy G, Sidoli S, Liu DD, Garcia BA, and Kang Y. Identification of nidogen 1 as a lung metastasis protein through secretome analysis. Genes Dev, 2017; 31(14):1439-55. interest. 
Anders CK, Carey LA. Biology, metastatic patterns and treatment of patients with triple-negative breast cancer. Clin Breast Cancer, 2009; 9(Suppl 2):S73-81.

Bacalbasa N, Ionescu O. Triple negative breast cancer current therapeutic options in the neoadjuvant setting. Educatie Medicala Continua, 2016; LXIII(q):65-68.

Bray F, Ferlay J, Soerjomataram I, Siegel RL, Torre LA, Jemal A. Global cancer statistics 2018: GLOBOCAN estimates of incidence and mortality worldwide for 36 cancers in 185 countries. CA Cancer J Clin, 2018; 68 (6):394-424.

Choi YK, Cho SG, Woo SM, Yun YJ, Park S, Shin YC, Ko SG. Herbal extract SH003 suppresses tumor growth and metastasis of MDAMB-231 breast cancer cells by inhibiting STAT3-IL-6 signaling. Mediat Inflamm, 2014; 2014:1-12.

Dai X, Li T, Bai Z, Yang Y, Liu X, Zhan J, Shi B. Breast cancer intrinsic subtype classification, clinical use and future trends. Am J Cancer Res, 2015; 5(10):2929-43.

Danen EHJ. Integrin signaling as a cancer drug target. ISRN Cell Biol, 2013; 2013:1-14.

De P, Aske JC, Dey N. RAC1 Takes the Lead in Solid Tumors. Cells, 2019; 8(382):1-17.

Diantini A, Subarnas A, Lestari K, Halimah E, Susilawati Y, Supriyatna, Julaeha E, et al. Kaempferol-3-O-rhamnoside isolated from the leaves of Schima wallichii Korth. inhibits MCF-7 breast cancer cell proliferation through activation of the caspase cascade pathway. Oncol Lett, 2012; 3(5):1069-72.

Friedl P, Wolf K. Tumour-cell invasion and migration: diversity and escape mechanisms. Nat Rev Cancer, 2003; 3(5):362-74.

Golubovskaya VM, Ylagan L, Miller A, Hughes M, Wilson J, Wang D, Brese E, Bshara W, Edge S, Morrison C, Cance WG. High focal adhesion kinase expression in breast carcinoma is associated with lymphovascular invasion and triple-negative phenotype. BMC Cancer, 2014; 14(1):1-8.

Halimah E, Diantini A, Destiani DP, Pradipta IS, Sastramihardja HS, Lestari K, Subarnas A, Abdulah R, Koyama H. Induction of caspase cascade pathway by kaempferol-3-O-rhamnoside in $\mathrm{LNCaP}$ prostate cancer cell lines. Biomed Rep, 2015; 3(1):115-17.

Horton ER, Humphries JD, Stutchbury B, Jacquemet G, Ballestrem C, Barry ST, Humphries MJ. Modulation of FAK and Src adhesion signaling occurs independently of adhesion complex composition. J Cell Biol, 2016; 212(3):349-64.

Howlader N, Noone A, Krapcho M, Miller D, Bishop K, Altekruse S, Kosary C, Yu M, Ruhl J, Tatalovich Z, Mariotto A, Lewis DR, Chen HS, Feuer EJ, Cronin KA. SEER Cancer Statistics Review 1975-2013. National Cancer Institute, Bethesda, MD, pp 1992-2013, 2016. Available via http://Seer.Cancer.Gov/Csr/1975_2013/, Based on November 2015 SEER data submission, posted to the SEER web site, April 2016.

Huveneers S, Danen EHJ. Adhesion Signaling - crosstalk between integrins, Src and Rho. J Cell Sci, 2009; 122 (8):1059-69.

Kim DH, Wirtz D. Focal adhesion size uniquely predicts cell migration. Faseb J, 2013; 27(4):1351-61.

Lewis KA, Jordan HR, Tollefsbol TO. Effects of SAHA and EGCG on growth potentiation of triple-negative breast cancer cells Cancers, 2019; 11(23):1-22.

Li Y, Li S, Meng X, Gan RY, Zhang JJ, Li H Bin. Dietary natural products for prevention and treatment of breast cancer. Nutrients, 2017; 9(7):1-38.

Lou S, Wang P, Yang J, Ma J, Liu C, Zhou M. Prognostic and clinicopathological value of rac1 in cancer survival: evidence from a metaanalysis. J Cancer, 2018; 9(14):2571-79.

Mack, NA, Whalley HJ, Castillo-Lluva S, Malliri A. The diverse roles of Rac signaling in tumorigenesis. Cell Cycle, 2011: 10(10):1571-81.

Mackay CR. Moving targets: cell migration inhibitors as new anti-inflammatory therapies. Nat Immunol, 2008; 9(9):988-98.

Morimura S, Takahashi K. Rac1 and stathmin but not EB1 are required for invasion of breast cancer cells in response to IGF-I. Int J Cell Biol, 2011; 2011:1-10.
Nobes CD, Hall A. Rho GTPases control polarity, protrusion, and adhesion during cell movement. J Cell Biol, 1999; 144(6):1235-44.

Ovcaricek T, Frkovic SG, Matos E, Mozina B, Borstnar S. Triple negative breast cancer-prognostic factors and survival. Radiol Oncol, 2011; 45(1):46-52

Rikitake Y, Takai Y. Directional cell migration. Regulation by small $\mathrm{G}$ proteins, nectin-like molecule-5, and afadin. 1st edition, International Review of Cell and Molecular Biology, Academic Press, Cambridge, MA, Vol. 287, 2011

Riss TL, Moravec RA, Niles AL, Duellman S, Bennink HA, Worzella TJ, Minor L. Cell viability assays. In Assay Guidance Manual. Eli Lilly \& Company and the National Center for Advancing Translational Sciences, Bethesda, MD, pp 1-31, 2016.

Sieg DJ, Hauck CR, Ilic D, Klingbeil CK, Schaefer E, Damsky $\mathrm{CH}$, and Schlaepfer DD. FAK integrates growth-factor and integrin signals to promote cell migration. Nat Cell Biol, 2000; 2(5):249-56.

Smith JA, Poteet-smith CE, Xu Y, Errington TM, Hecht SM, Lannigan DA. Identification of the first specific inhibitor of P90 ribosomal S6 kinase (RSK) reveals an unexpected role for RSK in cancer cell proliferation. Cancer Res, 2005; 65(3):1027-34.

Taliaferro-Smith LT, Oberlick E, Liu T, McGlothen T, Alcaide T, Tobin R, Donnelly S, Commander R, Kline E, Nagaraju GP, Havel L, Marcus A, Nahta R, O'Regan R. FAK activation is required for IGF1Rmediated regulation of EMT, migration, and invasion in mesenchyma triple-negative breast cancer cells. Oncotarget, 2015; 6(7):4757-72.

Tantivejkul K, Vucenik I, Shamsuddin AM. Inositol hexaphosphate (IP 6) inhibits key events of cancer metastasis : I in vitro studies of adhesion, migration and invasion of MDA-MB 231 human breast cancer cells. Anticancer Res, 2003; 23:3671-79.

Tsai CH, Chiu JH, Yang CW, Wang JY, Tsai YF, Tseng LM, Chen WS, Shyr YM. Molecular characteristics of recurrent triple-negative breast cancer. Mole Med Rep, 2015; 12(5):7326-34.

Utepbergenov D, Derewenda U, Olekhnovich N, Szukalska G, Banerjee B, Hilinski MK, Lannigan DA, Stukenberg PT, Derewenda ZS. Insights into the inhibition of the p90 ribosomal S6 kinase (RSK) by the flavonol glycoside SL0101 from the 15 crystal structure of the N-terminal domain of RSK2 with bound inhibitor. Biochemistry, 2012; 51(33):6499-510.

Volk-Draper L, Rajput S. Novel model for basaloid triplenegative breast cancer: behavior in vivo and response to therapy. Neoplasia, $2012 ; 14(10): 926-42$

Wells A, Grahovac J, Wheeler S, Ma B, Lauffenburger D. Targeting tumor cell motility as a strategy against invasion and metastasis. Trends Pharmacol Sci, 2013; 34(5):283-9.

Yoon H, Dehart JP, Murphy JM, Lim S-TS. Understanding the roles of FAK in cancer: inhibitors, genetic models, and new insights. J Histochem Cytochem, 2015; 63(2):114-28.

Zhang Z, Liang X, Gao L, Ma H, Liu X, Pan Y, Yan W, Shan $\mathrm{H}$, Wang Z, Chen YH, Ma C. TIPE1 induces apoptosis by negatively regulating Rac1 activation in hepatocellular carcinoma cells. Oncogene, 2015; 34:2566-74.

Zhu KC, Sun JM, Shen JG, Jin JZ, Liu F, Xu XL, Chen L, Liu LT, Lv JJ. Afzelin exhibits anti-cancer activity against androgen-sensitive LNCaP and androgen-independent PC-3 prostate cancer cells through the inhibition of LIM domain kinase 1. Oncology Lett, 2015; 10(4):2359-65.

How to cite this article:

Rachmi E, Purnomo BB, Endharti AT, Fitri LE. Afzelin inhibits migration of MDA-MB-231 cells by suppressing FAK expression and Racl activation. J Appl Pharm Sci, 2020; 10(1):077-082. 